\title{
On the occurrence of facultative paedomorphosis in the three newt species of Southern Iberian Peninsula (Amphibia, Salamandridae)
}

\author{
Francisco Ceacero $^{1, *}$, David Donaire-Barroso ${ }^{2}$, Enrique García-Muñoz ${ }^{3}$, \\ Juan Francisco Beltrán ${ }^{4}$, Miguel Tejedo ${ }^{5}$
}

\begin{abstract}
We report the occurrence of facultative paedomorphosis in the three species of newts (Pleurodeles waltl, Lissotriton boscai and Triturus pygmaeus) from dry and seasonal Mediterranean areas from southern Spain. These are the first records of paedomorphosis for $P$. waltl and L. boscai, and the second for T. pygmaeus. Other than the previous T. pygmaeus record, these are the first observations of paedomorphosis in the southern half of the Iberian Peninsula. Most of specimens demonstrating paedomorphosis live in artificially permanent aquatic environments. Nevertheless, a paedomorphic individual of $L$. boscai was found in a natural yearly temporary brook that held water during the previous two years. Paedomorphs are at low frequency in most cases. However, a single isolated population of $P$. walt is probably composed entirely of paedomorphs.
\end{abstract}

Keywords: Lissotriton boscai, paedomorphs, Pleurodeles waltl, Spain, Triturus pygmaeus.

Facultative paedomorphosis is widespread through caudate families and across a large diversity of environments (Wells, 2007). It is considered an adaptive strategy to highly heterogeneous aquatic/terrestrial environments due to the multitude of ecological and evolutionary trade-offs of each individual strategy (Denoël, Joly and Whiteman, 2005). Facultative paedomorphosis has been reported in several European newts of the former genus Triturus, including T. cristatus, T. carnifex, T. vittatus, Mesotriton alpestris, Lissotriton italicus, Lissotriton helveticus and L. vulgaris (Kalezic et al., 1996; Denoël and Joly, 2000; Denoël, 2003, 2007; Sindaco et al., 2006; Kaya et al., 2008;

1 - Departamento de Ciencia y Tecnología Agroforestal y Genética, ETSIA, UCLM, Campus Universitario s/n, 02071 Albacete, Spain

2 - Calle Mar Egeo 7, 11407 Jerez de la Frontera, Spain

3 - Departamento de Biología Animal, Biología Vegetal y Ecología. Campus de las Lagunillas s/n, Universidad de Jaén, 23071 Jaén, Spain

4 - Departamento de Fisiología y Zoología, Facultad de Biología, Universidad de Sevilla, Avda. Reina Mercedes 6, 41012 Sevilla, Spain

5 - Departamento de Ecología Evolutiva, Estación Biológica de Doñana, CSIC, Avda. Américo Vespucio s/n, 41092 Sevilla, Spain

*Corresponding author; e-mail:

francisco.ceacero@uclm.es
Denoël et al., 2009), showing a wide occurrence among species and with an apparent intraspecific geographic variation. Paedomorphosis occurs more commonly in southern Europe (the Alps and the Balkan and Italian Peninsulas; Denoël et al., 2001). However, few paedomorphic accounts exist at the Iberian Peninsula, which is inhabited by 10 species of native salamandrids. Most of the records correspond to large overwintering larvae: Chioglossa lusitanica, Salamandra salamandra, T. marmoratus (Salvador and García-París, 2001), T. pygmaeus (Reques, 2007), Pleurodeles waltl (Alberch and González, 1973; Alvarez, Salvador and Arguello, 1988; Bogaerts and van Uchelen, 2003), L. boscai (Bedriaga, 1896; O. Arribas, personal observation), L. helveticus (O. Arribas, personal observation), M. alpestris (Arribas, 2008), Calotriton asper (Campeny, Montori and Llorente, 1986). However, very few of these records were considered paedomorphs. The two reports of paedomorphosis are $M$. alpestris (species living at northern Spain) (Arribas, 2008), and a population of $T$. pygmaeus in southern Spain (Reques, 2007). Here we report the occurrence of paedomorphosis in three newt species: P. waltl, L. boscai and T. pygmaeus, from dry and seasonal Mediterranean 
Table 1. Characteristics of the aquatic environments where paedomorphs were found

\begin{tabular}{|c|c|c|c|c|c|}
\hline & Species & Locality & $\begin{array}{l}\text { Aquatic } \\
\text { habitat }\end{array}$ & $\begin{array}{c}\text { Drying } \\
\text { probability }\end{array}$ & $\begin{array}{l}\text { Terrestrial } \\
\text { habitat }\end{array}$ \\
\hline$\# 1$ & P. waltl & $\begin{array}{l}\text { Cañada de las Azadillas. Sa } \\
\text { Sur (Jaén). } 37^{\circ} 40 \mathrm{~N} 3^{\circ} 43 \mathrm{~W} \text {. } \\
880 \mathrm{~m} .\end{array}$ & $\begin{array}{l}60 \mathrm{~m}^{2} \text { swimming pool fed } \\
\text { by rain streams. Max. depth } \\
1 \mathrm{~m} .\end{array}$ & No & Pine wood forest. \\
\hline$\# 2$ & P. waltl & $\begin{array}{l}\text { El Cuervo (Sevilla). } 36^{\circ} 52 \mathrm{~N} \\
6^{\circ} 01 \mathrm{~W} .33 \mathrm{~m} .\end{array}$ & $\begin{array}{l}2.5 \mathrm{~m}^{2} \text { ancient agriculture } \\
\text { well. Max. depth } 4 \mathrm{~m} .\end{array}$ & No & Agricultural landscape. \\
\hline \#3 & T. pygmaeus & $\begin{array}{l}\text { Fuente la Zarza. Sierra Sur } \\
\text { (Jaén). } 37^{\circ} 46 \mathrm{~N} \quad 3^{\circ} 49 \mathrm{~W} . \\
740 \mathrm{~m} .\end{array}$ & $\begin{array}{l}5 \mathrm{~m}^{2} \text { round pond fed by } \\
\text { a small source. Max. depth } \\
0.5 \mathrm{~m} .\end{array}$ & No & $\begin{array}{l}\text { Pasture, scrubland and } \\
\text { pine wood. }\end{array}$ \\
\hline \#4 & L. boscai & $\begin{array}{l}\text { La Sorda. Sierra de Ara- } \\
\text { cena, (Huelva). } 37^{\circ} 54 \mathrm{~N} \\
6^{\circ} 34 \mathrm{~W} .660 \mathrm{~m} .\end{array}$ & $\begin{array}{l}1.5 \mathrm{~m}^{2} \text { small puddle rem- } \\
\text { nant of a dried temporary } \\
\text { brook. Max. depth } 0.5 \mathrm{~m} \text {. }\end{array}$ & High & $\begin{array}{l}\text { Mediterranean } \\
\text { scrubland. }\end{array}$ \\
\hline
\end{tabular}

areas from southern Iberian Peninsula, and describe their phenotypes and environments.

Sampled locations with paedomorphic individuals are shown in table 1 , and dates are indicated in the results section. In all cases, animals were captured by dip-netting. Body length was measured using digital calliper (mean $\pm \mathrm{SE}$ throughout the manuscript). Paedomorphs were assessed by observation of adult traits such as swollen cloacae, presence of nuptial pads and, eventually, courtship behaviour, in combination with very large size, open gill slits and morphology and colouration that either differed clearly from the larval phenotype. All the animals were subsequently released, although in some cases animals were transported to the laboratory for other research purposes. All ponds with paedomorphic newts were periodically monitored thereafter, although paedomorphs were not always observed again.

Pleurodeles walt paedomorphs were observed in two locations (\#1 and \#2; table 1). On June 17th 2007, a mature paedomorph male exhibiting adult and metamorph aspect and colouration, nuptial pads and swollen cloacae, was found in location \#1 (SVL = $88.0 \mathrm{~mm}$; $\mathrm{TL}=184.3$; fig. 1A). On January 31st 2009, a paedomorph female was observed at the same location $(\mathrm{SVL}=45.6 \mathrm{~mm}$; $\mathrm{TL}=82.8 \mathrm{~mm}$ ) with the same characteristics as the previously described individual. Paedomorphs in location \#2 were first visually recorded on March 17th 2007. This population was sampled on February 8th 2008, containing only paedomorphs $[\mathrm{SVL}=62.3 \pm 1.5 \mathrm{~mm}$ (range $=51.6-78.8$ $\mathrm{mm}), \mathrm{TL}=132.7 \pm 2.6 \mathrm{~mm}($ range $=105.7-$ $172.1 \mathrm{~mm}), n=13]$. All individuals exhibited sexual characters such as swollen cloacae and strong forelimbs with black nuptial pads. The coloration was dark brownish with small blots. The gill slits remained open. One male and one female paedomorph were transported to the lab and to date (May 2010) none of them resumed to metamorphosis. In January 2010 they were observed in amplexus. On March 12th 2010, we captured two distinct groups of individuals widely different in size: larvae $[\mathrm{TL}=37.2 \pm 1.1$ $\mathrm{mm}($ range $=30.1-41.2 \mathrm{~mm}), n=12]$ and large size paedormorphs, three males and one female, $[\mathrm{TL}=143.3 \pm 3.8 \mathrm{~mm}($ range $=121.2-162.3$ $\mathrm{mm}), n=4$ ], all of them branchiated and with swollen cloacae. Males did not exhibit nuptial pads.

Triturus pygmaeus paedomorphs were observed in location \#3 on April 1st 2005. Eleven individuals with two distinct phenotypes (regarding size and aspect) were captured. Paedomorphs $[\mathrm{SVL}=36.3 \pm 1.4 \mathrm{~mm}$ (range $=32.5$ $41.3 \mathrm{~mm}), \mathrm{TL}=74.0 \pm 1.6 \mathrm{~mm}($ range $=$ 65.7-83.7 mm), $n=4$, fig. 1B] were clearly bigger than larvae $[\mathrm{SVL}=18.2 \pm 0.3 \mathrm{~mm}$ $($ range $=16.7-19.9 \mathrm{~mm}), \mathrm{TL}=36.1 \pm 0.7 \mathrm{~mm}$ (range $=33.0-40.3 \mathrm{~mm}), n=7]$. Paedomorphs showed a similar and opaque colouration to that of the adults and metamorphs from the same population, with swollen cloacae and extension of caudal and dorsal fins similar to adult males, while larvae showed the normal traits and their normal translucent colouration. This population was subsequently monitored in 2007 and 2009, but no paedomorph was observed. 


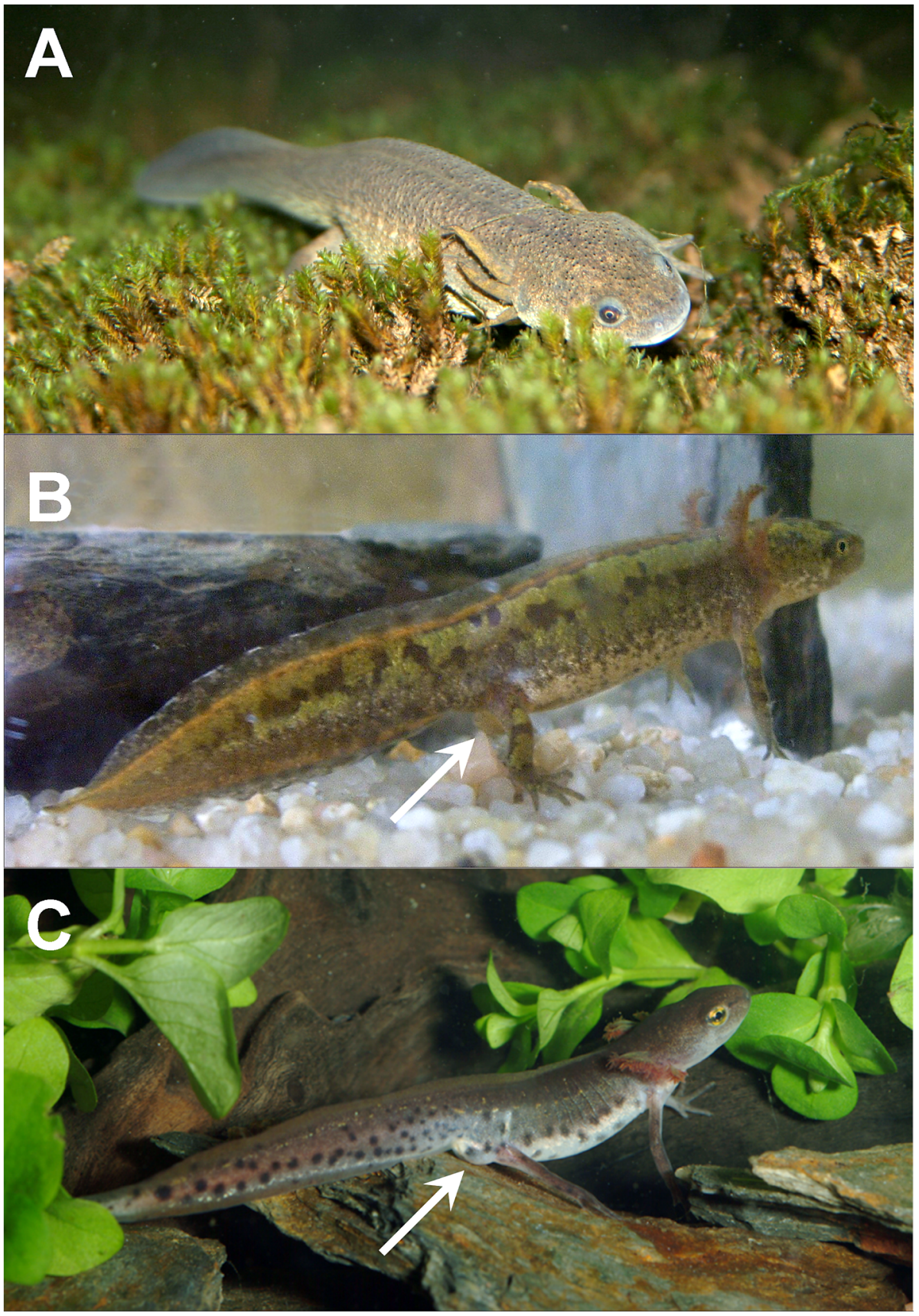

Figure 1. (A) Pleurodeles walt paedomorph male from location \#1. Note the adult colouration and the absence of dorsal crest (larval trait). (B) Triturus pygmaeus paedomorph male from location \#3. Note the adult colouration and the swollen cloaca (white arrow). (C) Lissotriton boscai paedomorph male from location \#4. Note the adult colouration and the swollen cloaca (white arrow). 
A Lissotriton boscai paedomorph male was captured in location \#4 on September 8th 2004 $(\mathrm{SVL}=30.6 \mathrm{~mm}, \mathrm{TL}=63.6 \mathrm{~mm})$, which exhibited a mosaic of juvenile and male adult traits. Dorsal coloration was brownish with some black spots along the tail and body sides. Belly was yellowish with a swollen rounded cloaca with a long obvious opening. Additionally, it exhibited a small tail crest and a tiny filament of around 2-3 $\mathrm{mm}$ at the end of the tail (fig. 1C). The paedomorph was maintained in the lab and on October 10th 2004 courtship activity was observed and voluntarily repeated for several days. The newt was kept during three months in the lab until it was released. Courtship behaviour was repeatedly observed and no signs of metamorphosis were evidenced to that date. No L. boscai larvae were found at this later date, suggesting that remaining larvae resumed metamorphosis during late spring and summer. This locality was periodically sampled since 2004 but no other paedomorph has been recorded to date.

This report describes the occurrence of paedomorphosis in the three newt species occurring in southern Iberia. Paedomorphosis is described for the first time in P. walt and L. boscai, since previously both species only had records for non-paedomorphs big size larvae (Bedriaga, 1896; Alberch and González, 1973; Alvarez, Salvador and Arguello, 1988; Bogaerts and van Uchelen, 2003; O. Arribas, personal observation); and the second record of paedomorphosis in T. pygmaeus (see Reques, 2007).

$P$. waltl paedomorphs were found in manmade permanent aquatic habitats with no presence of predatory fishes (Collins, Zerba and Sredl, 1993), although intraspecific cannibalism in $P$. waltl has been observed at location $\# 1$ and it seems likely at location \#2. In general, paedomorphs of $P$. waltl at location \#1 and T. pygmaeus at location \#3 coexisted in a very low frequency with metamorphic individuals. However, $P$. waltl population at location \#2, which inhabits a steep-sided and narrow well that rarely oscillates in its water level, was com- prised of only paedomorphs. No metamorphic individuals were found during two samplings, thus suggesting that it may be a completely paedomorphic population. Interestingly, a $P$. walt metamorphic population occupies a wider and bigger nearby well, less than $200 \mathrm{~m}$ away. $T$. pygmaeus paedomorphs were also observed in a permanent natural source, however, the paedomorphic male of L. boscai was found in a puddle within a temporary creek which generally desiccates each summer. This sexually mature individual presumably had a maximum age of one-two years, since the puddle had lasted approximately two years without drying. Thus, the specimen could have attained its large size and maturity during that time. However, no evidence of paedomorphic newts has been found to date despite intensive sampling of nearby permanent environments, thus suggesting that the frequency of this alternative developmental pathway is very low in this species.

In conclusion, southern Iberian newts seem to maintain the capacity to exhibit alternative developmental pathways under different kinds of environmental conditions. Thus, our observations suggest that paedomorphosis, although rare, seems to be relatively widespread in southern Iberia than often thought, and deserves more attention to explain its maintenance.

Acknowledgements. The authors wish to thank A. Hidalgo-Pontiveros and L. Pedrajas for their help during field trips, A. Conejo for the picture of L. boscai larvae, and J. Leonard for the useful suggestions and linguistic revision. Animals transported to the laboratory were collected with the authorisation of the "Consejería de Medio Ambiente de la Junta de Andalucía”.

\section{References}

Alberch, P., González, D. (1973): Notas sobre la distribución, biotopo, morfología y biometría de Pleurodeles waltl Michahelles en el NE de la Península Ibérica (Amphibia, Salamandridae). Misc. Zool. 3: 71-82.

Alvarez, J., Salvador, A., Arguello, J.A. (1988): Desarrollo larvario del gallipato (Pleurodeles waltl) en una charca temporal del noroeste Ibérico (Amphibia: Salamandridae). Ecología 2: 293-301. 
Arribas, O. (2008): Neotenia y longitud excepcional en Mesotriton alpestris de Fuentes Carrionas (Palencia). Bol. Asoc. Herpetol. Esp. 19: 23-24.

Bedriaga, J. von (1896): Die lurchfauna Europa. II. Urodela Schwanzlurche. B. Soc. Imp. Nat. Moscou 10: 38-705.

Bogaerts, S., van Uchelen, E. (2003): Fund einer riesenlarve des rippenmolches, Pleurodeles walt Michaelles, 1830, in der provinz Huelva, Spanien. Sauria 25: 13-15.

Campeny, R., Montori, A., Llorente, G.A. (1986): Nuevos datos sobre la permanencia de caracteres larvarios en individuos adultos de una población de tritón pirenaico (Euproctus asper) en el valle de Aran. Doñana, Acta Vertebrata 13: 170-173.

Collins, J.P., Zerba, K.E., Sredl, M.J. (1993): Shaping intraspecific variation: development, ecology and the evolution of morphology and life history variation in tiger salamanders. Genetica 89: 167-183.

Denoël, M. (2003): How do paedomorphic newts cope with lake drying? Ecography 26: 405-410.

Denoël, M. (2007): Priority areas of intraspecific diversity: Larzac, a global hotspot for facultative paedomorphosis in amphibians. Anim. Conserv. 10: 110-116.

Denoël, M., Joly, P. (2000): Neoteny and progenesis as two heterochronic processes involved in paedomorphosis in Triturus alpestris (Amphibia, Caudata). Proc. R. Soc. Lond. B Biol. Sci. 267: 1481-1485.

Denoël, M., Duguet, R., Dzukic, G., Mazzotti, S. (2001): Biogeography and ecology of paedomorphosis in Triturus alpestris (Amphibia, Caudata). J. Biogeogr. 28: 1271-1280.
Denoël, M., Joly, P., Whiteman, H.H. (2005): Evolutionary ecology of facultative paedomorphosis in newts and salamanders. Biol. Rev. 80: 663-671.

Denoël, M., Ficetola, G.F., Ćirović, R., Radović, D., Džukić, G., Kalezić, M.L., Vukove, T.D. (2009): A multi-scale approach to facultative paedomorphosis of European newts (Salamandridae) in the Montenegrin karst: Distribution pattern, environmental variables, and conservation. Biol. Conserv. 142: 509-517.

Kalezic, M.L., Cvetkovic, D., Djorovic, A., Dzukic, G. (1996): Alternative life-history pathways: paedomorphosis and adult fitness in European newts (Triturus vulgaris and T. alpestris). J. Zool. Syst. Evol. Res. 34: 1-7.

Kaya, U., Sayım, F., Başkale, E., Çevik, I.E. (2008): Paedomorphosis in the banded newt, Triturus vittatus (Jenyns, 1835). Belg. J. Zool. 138: 196-197.

Reques, R. (2007): Tritón pigmeo - Triturus pygmaeus. In: Enciclopedia Virtual de los Vertebrados Españoles. Carrascal, L.M., Salvador, A., Eds, Madrid, Museo Nacional de Ciencias Naturales.

Salvador, A., García-París, M. (2001): Anfibios Españoles. Talavera de la Reina, Canseco Eds.

Sindaco, R., Doria, G., Razzetti, E., Bernini, F. (2006): Atlas of Italian Amphibians and Reptiles. Firenze, Edizioni Polistampa.

Wells, K.D. (2007): The Ecology and Behaviour of Amphibians. Chicago, The University of Chicago Press.

Received: January 14, 2010. Accepted: May 23, 2010. 